\title{
DELINEATION AND MAPPING OF MICRONUTRIENTS STATUS THROUGH GIS TECHNIQUE FOR ARECANUT GARDENS UNDER TRADITIONAL AND NON- TRADITIONAL AREAS OF KARNATAKA
}

\author{
DINESH KUMAR. M, BINNY GOPAL \& B. C. DHANANJAYA \\ Department of Agronomy, College of Agriculture, University of
}

Agriculture and Horticultural Sciences, Navile, Shivamogga, Karnataka, India

\begin{abstract}
Delineation of spatial distribution of micronutrients was studied from 232 acres covering 65 arecanut farmers representing different eco-systems such as traditional hilly, extended non-traditional areas under tank fed, bore well fed and canal fed irrigation in Shivamogga, Chikkamagaluru and Davanagere districts of Karnataka, India. The chosen gardens were 15-18 years old with medium management. The standard technique of grid method with a spacing of $50 x 50$ $m$ was employed to draw soil samples from the selected study area at 0-30 $\mathrm{cm}$ depth with Geo-referencing through GPS identity. Samples were analyzed for DTPA (DI-ethylene Tri-amine Penta Acetic acid) extractable iron, manganese, copper and zinc. Nutrient index values, fertility ratings and percentage deficiency were calculated from the analytical results. Using these data in a GIS environment, fertility mapping of each area was done. Traditional area had acidic soils while others are basic in reaction. Among the different micronutrient studied iron, manganese and copper are in sufficiency level. Zinc was found to be deficient and critical in traditional, tank fed and bore well fed situations. Kerehosalli of bore well fed area and Chikkingala of tank fed are recorded lower zinc status with nutrient index value of 1.28 and 1.82 with low and inadequate fertility status and demands keen attention for management.
\end{abstract}

KEYWORDS: Arecanut, Grid, GIS, Nutrient Index Value \& Site Specific

Received: Apr 13, 2017; Accepted: May 02, 2017; Published: May 15, 2017; Paper Id.: IJASRJUN201722

\section{INTRODUCTION}

Arecanut belongs to family Palmae, is one of the economically important plantation crops grown in India. The economic part of the palm is called 'betel nut', mainly consumed as masticatory purpose in many parts of Asia. India ranks first in area $(0.45 \mathrm{mha})$ and production $(0.74 \mathrm{mt})$ of areanut in the world (Anon., 2016). Karnataka is one of the important Areca producing states contributing nearly 60 per cent $(0.46 \mathrm{Mt})$ to its country's total. The crop is traditionally well acclimatized in coastal and hilly zone situations of lateritic soils of undulating topography with moderate to heavy rainfall. Being a top plantation commercial crop, the cultivation is extending across all situations, including clay soil belts of non traditional areas.

The influence of soil parameter is one of the main factors governing the Phyto availability of an element (Kabata-Pendias, 2004). Nutrient uptake of the plant is affected by many soil parameters such as nutrient concentrations, $\mathrm{pH}$, cation exchange capacity, organic carbon etc apart from types and varieties of plants with their age. Hence, adequate nutrition to plants depends on many factors such as the ability of soils to supply the nutrients, rate of absorption of nutrients by plants, distribution of nutrients to functional sites and nutrient mobility within the plant (Bell and Dell, 2008). Hartemink (2005) stated that large quantities of nutrients are immobilized in the above 
and below ground of perennial crops paving way for lesser efficiency. The serious concerns in arecanut cultivation are huge yield gap from location to location, sustained nutrient requirement and low nutrient use efficiency (Bhat and Sujatha, 2009). Farmers are practicing imbalanced fertilizer application totally neglecting micronutrients giving specificity for micronutrients that to a blind application based on many other considerations than plant requirement. Location wise also, application differs. Coastal and hilly tract farmers rely more on the available source of bio-wastes while the farmers of transitional and dry tracts do apply tank silt, red earth, etc. to get higher yields from plants. In all cultivated soils, the micronutrient deficiency became common, demanding its application in a right proportion to harness better yields. The major reasons for deficiency includes high yielding varieties and their mining capacity, demand pattern, addition of organic manures and other related cultural practices apart from soil features such as clay content, base saturation, availability of different types, salt levels and organic matter for chelation, etc. (Sharma and Chaudhary, 2009; Fageria, 2001). Soils deficits in their ability to supply micronutrients are alarmingly widespread with intensification of cropping systems within the cultivated areas. An approach towards justifying such concerns is a site specific nutrient management wherein spatial variations are under consideration for exacting fertilizer applications. Considering these points, a study was undertaken to assess the micronutrients variability in the farmers Areca gardens of both traditional and non-traditional tracts to derive site specific variations. The spatial information is meaningfully derived using a powerful tool like GIS for soil fertility maps.

\section{MATERIALS AND METHODS}

Arecanut is being grown in different eco-systems in Karnataka. Depending on the variability in topography, soils and water supply, four different situations of arecanut growing area such as the traditional belt of hilly zone, extended nontraditional areas under canal fed belt, tank fed belt and bore well fed belt were chosen for the study in three different districts as shown in the figure. The study was conducted during 2013-14. In all these study areas, the crop was around 1518 year old with medium management representing Shivamoga, Chikkamagaluru and Davanagere districts of Karnataka, India covering 232 acres of 65 farmers. The details are given in table 1.

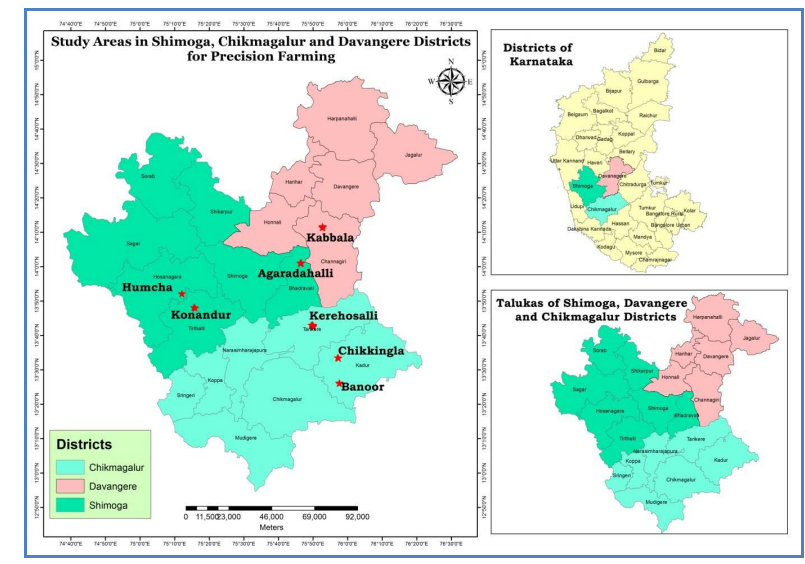

Figure 1: Different Study Area of Arecanut 
Table 1: Details of Different Sites of the Study Area

\begin{tabular}{|c|c|c|c|c|c|c|}
\hline \multirow{3}{*}{ Item } & \multirow{3}{*}{$\begin{array}{c}\text { Traditional } \\
\text { Area }\end{array}$} & \multicolumn{5}{|c|}{ Non-Traditional Area } \\
\hline & & \multicolumn{2}{|c|}{ Tank Fed Area } & \multirow{2}{*}{$\begin{array}{c}\text { Bore Well } \\
\text { Fed Area } \\
\text { Kerehosalli }\end{array}$} & \multicolumn{2}{|c|}{ Canal Fed Area } \\
\hline & & Banoor & Chikkingala & & $\begin{array}{c}\text { Agarada- } \\
\text { Halli }\end{array}$ & Kabbala \\
\hline No. of farmers & 14 & 6 & 8 & 11 & 19 & 7 \\
\hline Area (Acres) & 42 & 23 & 25 & 38 & 54 & 50 \\
\hline No. of samples & 66 & 47 & 50 & 61 & 86 & 80 \\
\hline $\mathrm{pH}$ range & $5.24-6.61$ & $7.29-8.64$ & $7.91-8.66$ & $7.06-8.27$ & $6.10-8.06$ & $6.82-8.62$ \\
\hline Soil reaction & Acidic & Basic & Basic & Basic & Basic & Basic \\
\hline
\end{tabular}

The standard technique of grid $(50 \times 50 \mathrm{~mm})$ method was employed to draw soil samples from the selected study area in 0-30 cm depth. Each grid is recognized by its own GPS coordinates (latitude and longitude) to make area Georeferenced. Further, using GPS coordinates, the base maps of the study area were developed by using GIS software. After taking soil samples from each grid, the soil was dry, powdered, sieved with $2 \mathrm{~mm}$ mesh and analyzed by following the standard methods of analysis. The metal ion iron, zinc, manganese and copper were extracted with DTPA extraction adjusted to $\mathrm{pH}$ 7.3+/- 0.5 using 1:1 dilute $\mathrm{HCl}$ at 1:2 ratio (soil: extraction) and estimation was done using Atomic Absorption Spectrometer (Lindsey and Norvell, 1957). The soil samples were categorized into low $\left(<3.7 \mathrm{mg} \mathrm{kg}^{-1}\right)$, medium (3.7-8.0 $\left.\mathrm{mg} \mathrm{kg}^{-1}\right)$ and high $\left(>8 \mathrm{mg} \mathrm{kg}^{-1}\right)$ for Fe, low $\left(<1.2 \mathrm{mg} \mathrm{kg}^{-1}\right)$, medium $\left(1.2-1.8 \mathrm{mg} \mathrm{kg}^{-1}\right)$ and high $\left(>1.8 \mathrm{mg} \mathrm{kg} \mathrm{kg}^{-1}\right)$ for $\mathrm{Cu}$, low ( $\left.<0.5 \mathrm{mg} \mathrm{kg}^{-1}\right)$, medium $\left(0.5-1.0 \mathrm{mg} \mathrm{kg}^{-1}\right)$ and high $\left(>1.0 \mathrm{mg} \mathrm{kg}^{-1}\right.$ ) for zinc (Reshma et al., 2016; James Brown et al., 2004). Also with the help of soil analytical results for different micronutrients on grid basis, fertility maps were prepared based on low and high classification criteria for each of them on a base map of each study location with the help of GIS. The points having the same category were grouped into class as a polygon by using inverse distant weighed method interpolation technique and maps for the individual nutrients were generated using GIS.

Nutrient Index Values were calculated using the following formula

$$
\mathrm{NIV}=\left[\left(\mathrm{PH}^{*} 3\right)+(\mathrm{PM} * 2)+(\mathrm{PL} * 1)\right] / 100
$$

Where, PH, PM and PL are the percentage of soil sample falling in the category of high, medium and low status given a weightage factor of 3, 2 and 1 respectively (Ramamurthy and Bajaj, 1967). Fertility rate and corresponding index values are given in table 2. For each location depending on its site specific variations, nutrient application approaches for the future with respect to different micronutrients is advised for farmers.

Table 2: Different Fertility Ratings for Nutrient Index Value

\begin{tabular}{|l|c|}
\hline \multicolumn{1}{|c|}{ Fertility Rating } & Nutrient Index Value \\
\hline Very high & $>2.67$ \\
\hline High & $2.33-2.66$ \\
\hline Adequate & $2.00-2.32$ \\
\hline Marginal & $1.67-1.99$ \\
\hline Low & $1.33-1.67$ \\
\hline Very low & $<1.33$ \\
\hline
\end{tabular}




\section{RESULTS AND DISCUSSIONS}

The location wise compiled soil analytical results for micronutrients are presented in table 3. Soil variability map for zinc in the study area is accomplished from Figure 2. The discussions based on different crop growing situations are given hereunder.

Traditional Area: This area is represented by Humcha and Konandur of Shivamogga district. This is a typical hilly zone cool area having rainfall around $2800 \mathrm{~mm}$ spread over from June to November. The soils are typically lateritic in nature, acidic in reaction, leaching of cations with fixation of $\mathrm{P}$ and $\mathrm{Zn}$ is a common feature. In the selected garden of arecanut, among the different micronutrients studied, iron, copper and manganese were found high in status. These variations are probably due to better organic matter management that helped to retain cations through chelation despite the acidic nature of soil with higher rainfall situations (Mahesh Kumar et al., 2015). On the other hand, zinc ranged from 0.28 to $3.43 \mathrm{mg} \mathrm{kg}^{-1}$ with a mean value of $0.8 \mathrm{mg} \mathrm{kg}^{-1}$. Nearly about 15,60 and 25 per cent of samples were grouped under low, medium and high status category, thereby achieving nutrient index value of 2.08 classified as adequate. It is well established that the unavailability of zinc is mainly due to the availability pool rather than total content (Brar et al., 2008). Lower levels may be attributed to temperature fluctuations, lower turnover of organic matter, low organic carbon and continuous demand from the crop. Similar results were also obtained in the studies of Shetty et al. (2008) in Areca gardens. Hence, in future, zinc supply needs attention in these areas.

Tank Fed Area: Tank fed area is represented by Banoor and Chikkingala of Chickamagaluru district, a shadow area just beside the hilly zone. The tanks nearby were filled due to the rains of hilly zone and the collected water sustains the perennial crops during off rainy seasons. These places receive around $550 \mathrm{~mm}$ rainfall and majority of soils are basic in nature. The virginity of soil is lost due to continuous growing situations and experiences more of abiotic stress situations like variation in temperature, relative humidity, sunshine hours, etc. Both locations recorded higher status of iron, manganese and copper. However, as compared to the previous location, there is a drastic decrement in the values for each location. Iron in particular often remained precipitated as iron hydroxide (Sharma et al., 2003) in alkaline soils but organic management can overcome these situations. Tank fed area soils are basic in nature and amount of variation exists for different nutrient largely depends on management factor and well supported in the studies of Sabita Soman and Byju (2013). Out of the samples analyzed, 93 and 07 per cent banner soils are medium and high for zinc status while Chikkingala soils had shown 30,58 and 12 percent of soils respectively for low, medium and high status. Banner soils with NIV of 2.06 attained an adequate fertility rating while Chikkingala soils with 1.82 NIV credited as marginal. These variations are mainly attributed to supply from various sources, as the plants grow up there demand remains low, reserved sauce, etc. Majorly management and supply pattern from different sources are the probable reason for these variations. Among the micronutrients, zinc may limit the yields in future if sufficient care is not taken up.

Bore Well Fed Area: Bore well supported Areca garden is represented by Kerehosahalli of Tarikere Taluk, Chikkamagaluru district, almost a continued stretch of a piece of land to that of the previous. With almost the same amount of rainfall $(510 \mathrm{~mm})$, in the absence of any irrigation sources, farmers are opting bore wells extensively for irrigation and hence opting perennial crops. These soils are again basic in nature and trend remained same as that of the previous location in that iron, manganese and copper remained high status with larger variations for zinc. The zinc content of the soil samples varied from 0.04 to $4.36 \mathrm{mg} \mathrm{kg}^{-1}$ with a mean value of $1.33 \mathrm{mg} \mathrm{kg}^{-1}$ in different grids indicating 74 per cent of samples low, 24 percent of the samples medium and 2 percent with high status achieved lowest NIV in 1.28 with a low 
fertility rating. Again, bore well fed soils are basic in nature and amount of variation exists for different nutrient contents as a result of management aspect, quality of irrigation water supplied over the years could also be evidenced from the studies of Barman et al. (2013) and Mahesh Kumar et al. (2015).

Canal Fed Area: Canal fed area is represented by Agaradahalli of Bhadravathi Taluk in Shivamogga district and Kabbala of Channagiri Taluk in Davangere district. Agaradahalli is blessed with Bhadra river canal while Kabbala is blessed with both Bhadra canal and as well Shantisagara tank feeder canal and hence assured source of irrigation. Agaradahalli soils are neutral to basic in reaction while Kabbala soils are tending towards basicity. Soil samples analyzed for different micronutrients across these locations recorded high status. Majorly management with supply of different sources are vital for these variations. These variations are also indicated in the studies of Dhanashekaran Pandian and Mohamed Haroon (2014). Sustained and balanced application of organic manures is the key factor for the high status of micronutrients. Organic matter is helpful in improving soil structure and aeration through increasing finer fractions, protects oxidation and precipitation of micronutrients into unavailable forms, supply soluble chelating agents which increase solubility of micronutrient content (Kumar and Babel, 2011).

\section{CONCLUSIONS}

Across the locations studied, it is found that iron; manganese and copper micronutrients are in sufficiency level. The locations in traditional, tank fed and bore well fed situations, zinc is not in sufficiency level and found crucial. Kerehosalli of bore well fed area and Chikkingala of tank fed are recorded lower zinc status and needs keen attention for sustained crop production.

\section{REFERENCES}

1. Anonymous, (2016) Area, production and productivity of arecanut. Indiastat.com

2. Barman, D., Saho, R.N., Kalra, N., Kamble, K. and Kundu, D.K. (2013) Homogenous soil fertility mapping through GIS for site specific nutrient management by QUEFTS model. Indian Journal of Soil Conservation 41(3):257-261.

3. Bell, R.W. and Dell, B. (2008). Micronutrients for Sustainable Food, Feed, Fibre and Bioenergy Production. First edition, IFA, Paris, France (www.fertilizer.org).

4. Bhat, R. and Sujatha, S. (2009) Soil fertility and nutrient uptake by arecanut as affected by level and frequency of fertigation in a laterrite soil. Agricutural water management 96(3):445-456.

5. Brar, M.S., Khurana, M.P.S., Sharma, P. and Malhi, S.S. (2008) Management practices to alleviate micronutrient stress in Indian soils. 17 th International Symposium of CIEC 24-27.

6. James R. Brown, Deanna K. Crocker, John D. Garrett, Roger G. Hanson, John A. Lory, Manjula V. Nathan, Peter C. Scharf and Howell N. Wheaton. (20040 Soil Test Interpretations and Recommendations Handbook. Original author : Daryl D. Buchholz, 1983, Division of Plant Sciences, College of Agriculture, University of Missouri: 32.

7. Dhanashekaran Pandiyan, R. and Mohamed Harron, A.R. (2014) Soil nutrient status mapping through GIS technique of direct seeding rice cultivating area of Ramnad district. Trends in biosciences 7(2):3722-3726.

8. Fageria, V. D. (2001). Nutrient Interactions in Crop Plants. Journal of Plant Nutrition 24 (8) : $1269-1290$.

9. Hartemink, A.E. (2005) Nutrient stocks, nutrient cycling and soil change in cocoa ecosystem: A review. Advances in Agronomy 86:227-253. 
10. Kabata-Pendias, A. (2004) Soil plant transfer of trace elements-an environmental issue. Geoderma 122:143-149.

11. Kumar M. and Babel A. L. (2011) Available Micronutrient Status and Their Relationship with Soil Properties of Jhunjhunu Tehsil, District Jhunjhunu, Rajasthan, India. Journal of Agricultural Science 3 (2): 97-106

12. Lindsay, W.L. and Norvell, W.A. (1978) Development of DTPA soil test for zinc, iron, manganese and copper. Soil Science Society of America Journal 42, 421-428.

13. Mahesh Kumar, Panwar, N.R., Pandey, C.R. and Jatav, M.K. (2015) Spatial distribution of available nutrients in the potato growing areas of Banaskantha district of Gujarath. Potato Journal 42(2): 130-136.

14. Ramamoorthy, B. and Bajaj, J.C. (1969) Available N, P and K status of Indian soils. Fertilizers News 14, 24-26.

15. Reshma M. R., Duraisami V. P., Mthumanickam D., Soniya purma and Jayasoorian N. (2016) Delineation and Mapping of Soil Available Iron and Copper Status in Soils of Salem District of Tamil Nadu Using GIS and GPS Techniques. International Journal of Agricultural Science and Research 6 (2): 295-300.

16. Sabitha Soman and Byju, G. (2013) Geospatial assessment and mapping of selected soil physical and chemical properties at Farm Level: A case study in an Ultisol. Journal of Root Crops 39(2):73-86.

17. Sharma, J.C. and Chaudhary, K. (2007) Vertical distribution of micronutrient cations in relation to soil characteristics in lower Shiwaliks of Solan district in north-west Himalayas. Journal of the Indian Society of Soil Science 55, 40-44.

18. Sharma, P.P., Singh, M. and Sharma, J.P. (2003) Correlation studies on micronutrients vis -a-vis soil properties in some soil of Nagpur district in semi arid region of Rajasthan. Journal of the Indian Society of Soil Science 51, 522-527.

19. Shetty, Y.V., Nagamma, M.S., Dinesh Kumar.M. and Jayaprakash, S.(2008) Fertility status in arecanut garden soils of Kanataka. Karnataka Journal of Agricultural sciences 21(4):503-506.

\section{APPENDICES}

Table 3: Mean, Range, Per Cent Sample Rating Category, NIV and Fertility Rating of Micronutrients for the Different Arecanut Area

\begin{tabular}{|c|c|c|c|c|c|c|c|c|}
\hline Parameters & $\mathrm{Fe}(\mathrm{ppm})$ & Mn (ppm) & Zn (ppm) & $\mathrm{Cu}(\mathrm{ppm})$ & Fe (ppm) & Mn (ppm) & $\mathbf{Z n}(\mathbf{p p m})$ & $\mathrm{Cu}(\mathrm{ppm})$ \\
\hline & \multicolumn{4}{|c|}{ HUMCHA AND KONANDUR } & \multicolumn{4}{|c|}{ CHIKKINGALA } \\
\hline Mean & 68.96 & 47.86 & 0.8 & 16.44 & 13.17 & 14.36 & 0.67 & 3.09 \\
\hline Maximum & 268.31 & 110.25 & 3.43 & 61.37 & 24.47 & 22.16 & 2.67 & 5.22 \\
\hline Minimum & 12.13 & 8.82 & 0.28 & 1.41 & 8.3 & 6.07 & 0.31 & 2.09 \\
\hline \multirow{3}{*}{$\begin{array}{l}\text { Per cent Ratings } \\
\text { of samples }\end{array}$} & Low-00 & Low-00 & Low-15 & Low-00 & Low-00 & Low-00 & Low-30 & Low-00 \\
\hline & Med-00 & Med-00 & Med-60 & Med-01 & Med-00 & Med-00 & Med-58 & Med-00 \\
\hline & High-100 & High-100 & High-25 & High-99 & High-100 & High-100 & High-12 & High-100 \\
\hline NIV & 3.00 & -- & 2.09 & 2.98 & 3.00 & -- & 1.82 & 3.00 \\
\hline \multirow[t]{2}{*}{ Fertility Rating } & Very high & -- & Adequate & Very high & Very high & -- & Marginal & Very high \\
\hline & \multicolumn{4}{|c|}{ KEREHOSAHALLI } & \multicolumn{4}{|c|}{ AGARADAHALLI } \\
\hline Average & 28.35 & 64.67 & 0.55 & 4.04 & 111.45 & 60.9 & 1.33 & 4.16 \\
\hline Maximum & 79.25 & 278.9 & 6.94 & 8.2 & 212.3 & 220.33 & 4.36 & 9.49 \\
\hline Minimum & 9.84 & 12.42 & 0.04 & 0.14 & 36.18 & 1.39 & 0.04 & 0.1 \\
\hline \multirow{3}{*}{$\begin{array}{l}\text { Per cent Ratings } \\
\text { of samples }\end{array}$} & Low-00 & Low- 00 & Low-74 & Low-02 & Low-00 & Low-04 & Low-00 & Low-52 \\
\hline & Med-00 & Med-00 & Med-24 & Med-05 & Med-00 & Med-00 & Med-45 & Med-24 \\
\hline & High-100 & High- 100 & High-02 & High-93 & High-100 & High-96 & High-55 & High-24 \\
\hline NIV & 3.00 & -- & 1.28 & 2.92 & 3.00 & -- & 2.56 & 1.71 \\
\hline \multirow[t]{2}{*}{ Fertility Rating } & Very high & -- & Low & Very high & Very high & -- & Very high & Marginal \\
\hline & \multicolumn{4}{|c|}{ BANOORU } & \multicolumn{4}{|c|}{ KABBALA } \\
\hline Average & 10.61 & 12.14 & 0.71 & 3.28 & 21.81 & 41.55 & 2.62 & 2.92 \\
\hline Maximum & 22.24 & 17.83 & 1.08 & 5.85 & 48.37 & 179.65 & 11.97 & 4.98 \\
\hline
\end{tabular}



Arecanut Gardens under Traditional and Non-Traditional Areas of Karnataka

\begin{tabular}{|l|c|c|c|c|c|c|c|c|}
\hline \multicolumn{10}{|c|}{ Table 3: contd., } \\
\hline Minimum & 4.91 & 6.99 & 0.42 & 2.39 & 7.3 & 14.86 & 0.51 & 1.14 \\
\hline \multirow{2}{*}{$\begin{array}{l}\text { Per cent Ratings } \\
\text { of samples }\end{array}$} & Low-00 & Low-00 & Low-00 & Low-00 & Low-00 & Low-00 & Low-00 & Low-03 \\
\cline { 2 - 10 } & Med-24 & Med-00 & Med-94 & Med-00 & Med-02 & Med-00 & Med-23 & Med-03 \\
\cline { 2 - 10 } & High-76 & High- 100 & High-06 & High-100 & High-98 & High-100 & High-77 & High-94 \\
\hline NIV & 1.97 & -- & 2.06 & 3.00 & 2.98 & -- & 2.78 & 2.93 \\
\hline Fertility Rating & Marginal & -- & Adequate & Very high & Very high & -- & Very high & Very high \\
\hline
\end{tabular}

NIV- Nutrient Index Value
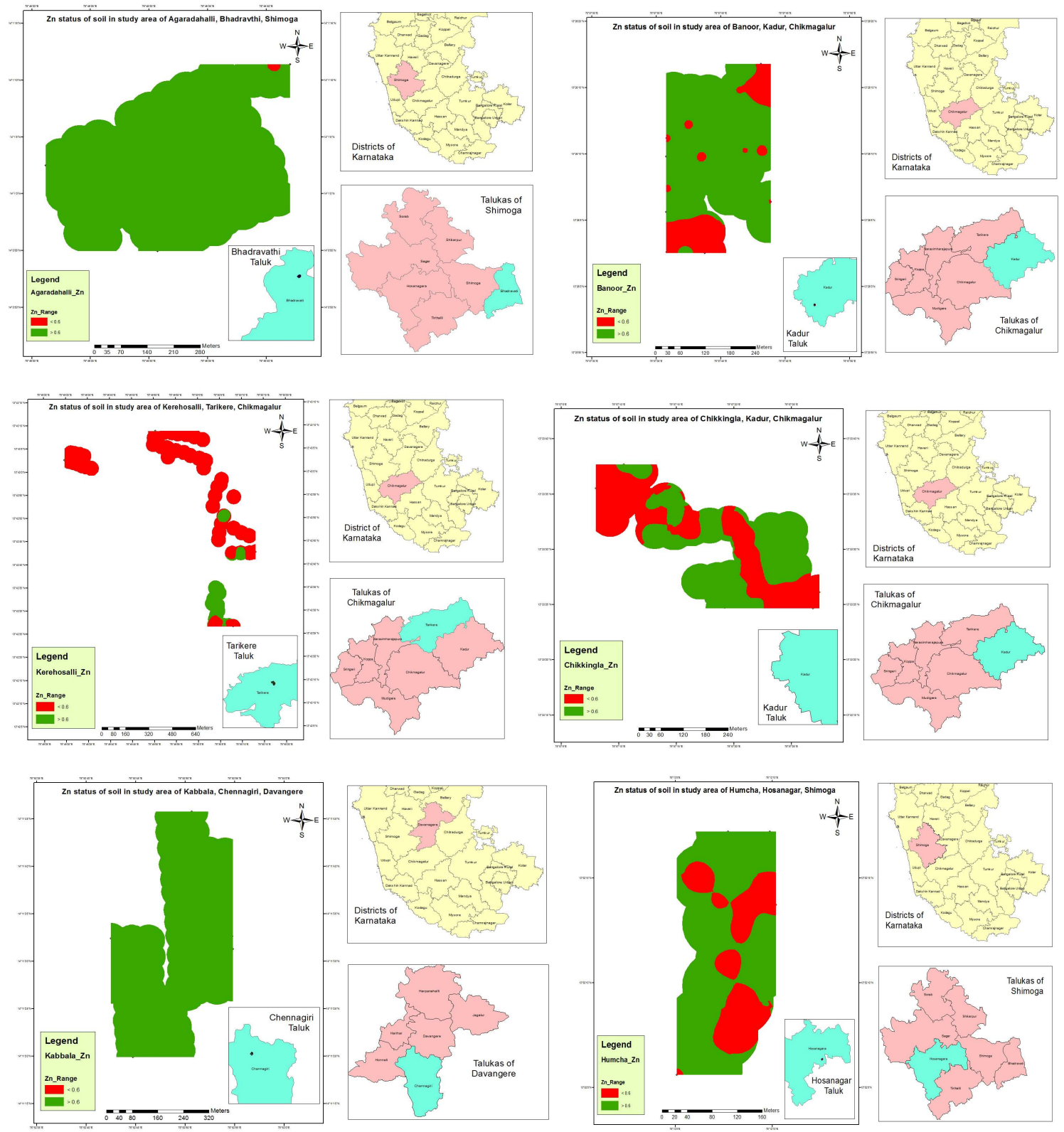

Figure 2: Zinc Status of Arecanut Gardens in Selected Study Area of Kanataka 

